\title{
Evaluación experimental de vacuna BCG y extracto proteico en bovinos, vía expresión de citocinas
}

Experimental evaluation of BCG vaccine and proteic extract in bovines, via cytokine expression

Avaliação experimental da vacina BCG e extrato proteico em bovinos, via da expressão citocinas

\author{
Maura Cruz-Fierro \\ Laura Jaramillo-Meza, \\ Clara Inés Espitia-Pinzón \\ Rafael Pérez-González 1 \\ Anabelle Manzo-Sandoval \\ Fernando Díaz-Otero ${ }_{2,4}$
}

Recibido: 27 de septiembre de 2019

Aprobado: 12 de noviembre de 2019

Publicado: 13 de enero de 2020

Cómo citar este artículo:

Cruz-Fierro M, Jaramillo-Meza L, Espitia Pinzón C, Pérez-González R, Manzo-Sandoval A, Díaz-Otero F. Evaluación experimental de vacuna BCG y extracto proteico en bovinos, vía expresión de citocinas. Spei Domus. 2020;16(1): 1-27. doi: https://doi.org/10.16925/2382-4247.2020.01.04

Artículo de investigación. https://doi.org/10.16925/2382-4247.2020.01.04

1 Facultad de Estudios Superiores-Cuautitlán, Universidad Nacional Autónoma de México (UNAM).

2 Salud Animal e Inocuidad. Instituto Nacional de Investigaciones Forestales, Agrícolas y Pecuarias. (INIFAP) SADER.

3 Laboratorio de Inmunología, Instituto de Investigaciones Biomédicas, (IIB) UNAM.

4 CENID-Salud Animal e Inocuidad, INIFAP. Departamento de Inmunología en Tuberculosis Bovina. Carretera México-Toluca, Km. 15.5 Col. Palo Alto, Cuajimalpa. Ciudad de México 05110, Tel: (0155) 38-71-87-00 ext. 80315.

Correo electrónico: diof0009@yahoo.com.mx 


\title{
Resumen
}

Introducción: La tuberculosis bovina (TBb) continúa siendo un problema grave para la salud pública y la sanidad animal, sobre todo en países en vías de desarrollo, en los cuales las prevalencias en los sistemas bovinos de leche pueden alcanzar cifras por encima del $40 \%$. En consecuencia, su control debe fundamentarse en alternativas integrales en su fuente animal para evitar su transmisión entre animales y a los seres humanos desde la perspectiva de "Una sola salud". La vacunación se considera la opción más viable para lograr disminuir su incidencia; sin embargo, para conseguir éxito en este propósito es necesario determinar las condiciones bajo las cuales debe aplicarse la vacuna, y comprender los mecanismos inmunológicos que ofrecen resistencia contra Mycobacterium bovis, pues siendo esta una bacteria intracelular es deseable que las vacunas induzcan una respuesta tipo Th1, caracterizada por la producción de interferón gamma (IFN- $\gamma$ ), factor de necrosis tumoral alfa (TNF-a) e interleucina 12 (IL-12), citocinas responsables de la activación y efecto microbicida de los macrófagos. Este estudio evaluó la eficacia vacunal de la vacuna BCG y del extracto proteico de filtrado de cultivo (CFPE) de M. bovis como inmunógenos contra la TBb, a través del monitoreo de la producción de IFN- $\gamma$, evaluación de la expresión de citocinas Th1 (IFN- $\gamma$, IL-2), Th2 (IL-4, IL-10), y presencia de lesiones macroscópicas a la necropsia tras el desafió.

Metodología: 24 becerras Holstein-Friesian de 6 meses de edad, negativas a diferentes pruebas inmunodiagnósticas de TBb, se dividieron en cuatro grupos (6 becerras/grupo): control no vacunado, vacunado con BCG, vacunado con CFPE de $M$. bovis AN5 y vacunado con CFPE, pero con tratamiento previo con IFN- $\gamma$ recombinante. La expresión de citocinas IFN- $\gamma$, IL-2, IL-4 e IL-10 se evaluó por RT-PCR y se representó como el porcentaje de la intensidad relativa de las bandas correspondientes con respecto al control positivo interno ( $\beta$-actina), utilizando el software LabsWorks 4.0. La respuesta inmune celular se evaluó mediante la producción de IFN- $\gamma$ en cultivo de células estimuladas con PPD bovino y PPD aviar, en diferentes periodos.

Resultados: La expresión de las citocinas fue diferente entre los grupos vacunados y control, tanto en el periodo posvacunal como posdesafío. La expresión de IFN- $\gamma$ en el grupo vacunado con BCG fue mayor ante el estímulo antigénico in vitro con el PPD bovino y con el antígeno DipZ en el tiempo posvacunación evaluado. En los grupos inmunizados con el CFPE, la expresión de IL-4 fue significativa durante ese periodo, sobre todo en el grupo tratado con el IFN- $\gamma$. Después del desafío, se incrementó la producción y expresión del IFN- $\gamma$ en todos los grupos; siendo 200 veces superior para el grupo tratado con IFN- $\gamma$ con los diferentes antígenos. En este grupo la mayor expresión de IL-2, IL-4 e IL-10 fue también significativa, sobre todo la de IL-10, reconocida antagonista de la inmunidad celular. De hecho, en este grupo vacunado se presentó el mayor número de lesiones al desafío; siendo, no obstante, menos severas que las del grupo control.

Conclusiones: En el grupo vacunado con BCG se registró el menor número y grado de lesiones, correlacionando con una producción y expresión significativa de IFN- $\gamma$. El tratamiento previo con IFN- $\gamma$ en el grupo inmunizado con CFPE mostró un efecto adverso en el establecimiento de una inmunidad protectora debido a una modulación negativa por parte de la IL-4 e IL-10. De acuerdo con los resultados, la BCG resultó ser el mejor inmunógeno en el estudio, por lo que su empleo como alternativa para el control de la enfermedad es promisorio.

Palabras clave: bovinos, citocinas, Interferón-gamma, tuberculosis, vacunas BCG

\begin{abstract}
Introduction: bovine tuberculosis (bTB) continues to be a serious public and animal health issue, specially in developing countries, in which prevalences in bovine dairy systems can reach numbers above $40 \%$. Consequently, its control must be grounded in whole alternatives for its animal source in order to prevent transmission between animals and human beings from a "one health" perspective. Vaccination is considered the most viable option to reduce its incidence; nonetheless, to achieve this purpose successfully is necessary to determine the conditions under which vaccine must be applied, and understand the immunological mechanisms giving resistance against mycobacterium bovis, since its an intracellular bacteria it is desirable that vaccines induce a Th1
\end{abstract}


Maura Cruz-Fierro, Laura Jaramillo-Meza, Clara Inés Espitia-Pinzón, Rafael Pérez-González, 3 Anabelle Manzo-Sandoval, Fernando Díaz-Otero

type response, characterized by gamma interferon production (IFNY), which is a tumor necrosis factor alpha (TNF) and interleukin 12 (IL-12), cytokines responsible for macrophage microbicide activation and effect. This study evaluated vaccination effectiveness of BCG vaccine and proteic extract filtered from a $\mathrm{m}$. Bovis (CFPE) culture as immuno agent against bTB, through monitoring of IFNy production, evaluation of cytokines Th1 expression (IFN-g, IL-2), Th2 (IL-4, IL-10), and the presence of macroscopic lesions towards necrosis after the challenge.

Methodology: 24 Holstein-Friesian calves of six months old, negative to different bTB immunodiagnostic tests, were devided in four groups (6 calves/group): not vaccined group, BCB vaccined, vaccinated with CFPE $\mathrm{m}$. Bovis AN5 and vccinated with CFPE, but with previous IFNy treatment. IFNy, IL-2, IL-4 and IL-10 cytokine expression was evaluated through RT-PCR and represented as the percentage of relative intensity to corresponding bands with respect to internal positive control (b-actin), using LabWorks 4.0 software. Immune cellular response was evaluated through IFNy production in cell culture estimated with bovine and avian PPD in different periods.

Results: cytokine expression was different between vaccinated and control groups, both in the postvaccinal and postchallenge periods. Expression of IFNy in vaccinated group with BCG was higher in front of in vitro antigen stimulation with bovine PPD and with DipZ antigen in the evaluated postvaccination period. Immunized groups with CFPE, expression of IL-4 was significant during that period, specially in group treated with IFNy. After challenge, production and expression of IFNY increased in all groups; being 200 times higher for the group treated with IFNY with different antigen. In this group, higher expression of IL-2, IL-4 and IL-10 was also significant, especially IL10, a known antagonist of cellular immunity. In fact, this vaccinated group presente the highest number of lesions to challenge; being, nonetheless, less severe than the ones in the control group.

Conclusions: the vaccinated group with BCG registered the lower number and degree of lesions, correlated with a significant IFNy expression and production. Previous treatment with IFNY in the immunized group with CFPE showed an adverse effect in the stablishment of a protective immunity due to a negative modulation from IL-4 and IL-10. According to the results, BCG is a better immune agent in the study, so that its use as an alternative for disease control is promising.

Keywords: bovine, cytokines, gamma interferon, tuberculosis, BCG vaccine.

\section{Resumo}

Introdução: a tuberculoses bovina (TBb) é um problema grave da saúde publica e da sanidade animal em países em via de desenvolvimento, apresentando prevalências nos sistemas bovinos de leite alcançando cifras por encima de $40 \%$. Por isto, seu controle se fundamenta em alternativas integrais em sua fonte animal para evitar sua transmissão entre animais e os seres humanos, desde a perspectiva de "Saúde Única". A opção mais viável para diminuir sua incidência é a vacina, porém, para conseguir com êxito, é necessário determinar as melhores condições para aplicar a vacina e entender os mecanismos imunológicos que oferecem resistência contra Mycobacterium bovis, sendo ela uma bactéria intracelular, é necessário produzir uma resposta Th1, caracterizada pela produção do interferon gamma IFN- $\gamma$ ), fator de necroses tumoral alfa TNF-a) e interleucina 12 (IL-12), citocinas responsáveis pela ativação e efeito microbicida dos macrófagos. Neste estudo avaliou-se a eficácia da vacina BCG e o extrato protéico filtrado de cultivo (CFPE) de $M$. bovis como imunógenos contra a TBb através da análise de produção IFN- $\gamma$, avaliação da expressão de citocinas Th1 (IFN- $\gamma$, IL-2), Th2 (IL-4, IL-10) e presença de lesões macroscópicas da necropsia após exposição.

Metodologia: 24 bezerras Holstein-Friesian de 6 meses de idade negativas a diferentes provas imunodiagnoticas de TBb se dividiram em 4 grupos ( 6 bezerras por grupo): controle sem vacina, vacina com BCG, vacina com CFPE de $M$. bovis AN5 e vacina com CFPE com tratamento prévio IFN- $\gamma$ recombinante. A expressão de citocinas IFN- $\gamma$, IL-2, IL-4 e IL-10 avaliou-se por RT-PCR e se apresentou com a percentagem de intensidade relativa das bandas correspondentes com respeito ao controlo positivo interno ( $\beta$-actina), utilizando-se software LabsWorks 4.0. A avaliação da resposta imune celular foi avaliada mediante o produção de IFN- $\gamma$ no cultivo de células estimuladas com PPD bovino e PPD avaliar em diferentes períodos. 
Evaluación experimental de vacuna BCG y extracto proteico en bovinos, vía expresión de citocinas

Resultados: A expressão das citocinas foi diferente entre os grupos de vacinas e controle, no período pós vacinal como pós desafio. A expressão de IFN- $\gamma$ no grupo vacinado com BCG foi maior entre o estímulo antigênico in vitro com o PPD bovino e com o antígeno DipZ no tempo pós vacinação avaliado. No grupo de imunizados com o CFPE, a expressão de IL-4 foi significativa neste período, apresentando maior porcentagem no grupo tratado com o IFN- $\gamma$. Após o desafio, se incrementou a produção e expressão do IFN- $\gamma$ em todos os grupos; sendo 200 vezes superior para o grupo tratado com IFN- com diferentes antígenos. Neste grupo a maior expressão do IL-2, IL-4 e IL-10 foi também significativa, apresentando IL-10 maior reconhecida antagonista da imunidade celular. De fato, neste grupo com BCG registrou-se o menor número e grado de lesões no desafio, manifestando-se no obstante menos severas em comparação do grupo controle.

Conclusões: no grupo vacinado com BCG mostrou um menor número e grado de lesões, correlacionando com uma produção e expressão significativa do IFN- $\gamma$. No tratamento prévio com IFN- $\gamma$ no grupo imunizado com CFPE mostrou um efeito adverso no estabelecimento da imunidade protetora devido a uma modelação negativa por parte da IL-4 e IL-10. De acordo com os resultados apresentando a BCG é o melhor imunógeno no estudo, sendo promissório seu uso no controle da doença.

Palavras chave: bovinos, citocinas, inteferon gamma, tuberculoses, vacinas BCG.

\section{Introducción}

La tuberculosis bovina (TBb) es una de las enfermedades zoonóticas más importantes a nivel mundial y representa un serio problema de salud pública, además de causar graves pérdidas económicas a la industria ganadera [1]. Los casos documentados de tuberculosis en humanos (TBh), ocasionada por M. bovis, se han ido incrementando en las últimas décadas [2]. Para reducir las prevalencias o incidencias de TBb, algunos países han implementado programas de control y erradicación, basados principalmente en la realización de las pruebas intradérmicas de la tuberculina, con la eliminación y sacrificio de los animales reactores [3]. Por otra parte, se han buscado alternativas de control que no conlleven el sacrificio de animales, una de ellas es el empleo de vacunas que protejan a largo plazo y controlen la TBb [4] y [5].

Mayormente, se necesitan estrategias innovadoras para preparar mejores herramientas basadas en la identificación de nuevos antígenos importantes para el desarrollo de pruebas de diagnóstico que podrían ser, no solo más precisas y sensibles, sino también capaces de diferenciar a los animales vacunados infectados y no infectados (pruebas "DIVA"), ofreciendo así perspectivas para introducir la vacunación potencial dentro de los programas de erradicación existentes [6].

En consecuencia, el enfoque One Health se considera una necesidad crítica para abordar las enfermedades zoonóticas. El concepto One Health es una estrategia mundial para expandir las colaboraciones y comunicaciones interdisciplinarias en todos los aspectos de la atención médica para humanos, animales y el medio ambiente. En lo que respecta a la enfermedad de la tuberculosis, esta estrategia puede acelerar 
Maura Cruz-Fierro, Laura Jaramillo-Meza, Clara Inés Espitia-Pinzón, Rafael Pérez-González, 5

Anabelle Manzo-Sandoval, Fernando Díaz-Otero

el desarrollo de nuevas pruebas de diagnóstico para humanos y ganado, pero también mejorar los programas de vigilancia, control y erradicación de la tuberculosis [7].

Actualmente los desarrollos se orientan hacia la investigación de antígenos propios de la vacuna de $M$. bovis BCG, que permitan diferenciar la respuesta inmune de aquella inducida por cepas patógenas de M. bovis [8] y [9].

Por otro lado, se han desarrollado vacunas a nivel experimental con dosis de $10^{6}$ y $10^{9}$ Unidades Formadoras de Colonias (UFC), consideradas medias y altas de $B C G$, respectivamente; que al ser evaluadas evocan la secreción de citocinas relacionadas con la protección a la enfermedad, por ejemplo: el IFN- $\gamma$ e IL-2. Sin embargo, se ha mencionado que la vacunación con BCG puede interferir con los métodos de diagnóstico convencionales (pruebas intradérmicas de tuberculina). No obstante, tal reactividad al PPD bovino parece estar más relacionada con factores como la dosis de vacuna BCG empleada, la edad del animal al momento de la aplicación, la variedad de cepa de BCG utilizada, junto con la sensibilización previa a la vacunación por micobacterias ambientales [10].

En ese orden de ideas, se requiere una vacuna de fácil aplicación, efectiva para el control, y que no interfiera con el diagnóstico de la enfermedad. Una de las razones para que se genere la interferencia diagnóstica, tiene que ver con las altas dosis de BCG que han sido aplicadas [9].

La vacunación es un componente importante para el control de diferentes enfermedades de origen infeccioso, por lo que la TBb no debería estar exenta de esta estrategia. La única vacuna aceptada para el control de la enfermedad en humanos es la BCG de M. bovis, la cual se originó a partir de una cepa de M. bovis virulenta proveniente de un caso de mastitis bovina en el año de 1908. La BCG se ha aplicado en humanos desde 1921, lo que la convierte en la vacuna del campo de la salud humana más utilizada a nivel mundial [11] y [12].

En la década de los 20 del siglo pasado, se observó que la BCG aplicada en bovinos, vía intradérmica, confería protección 30 días posvacunación con una dosis alta única de $100 \mathrm{mg}$ ( 109 UFC), protegiendo al ganado de infecciones naturales y experimentales. Al vacunar animales recién nacidos se observó que estaban libres de lesiones de TBb al sacrificio [13].

Como alternativa vacunal, se han utilizado los extractos proteicos de filtrado de cultivo (CFPE, por sus siglas en inglés) de M. bovis o M. tuberculosis, que en diferentes estudios han mostrado ser potentes estimuladores de linfocitos $T$, tanto en modelos de ratones como en bovinos [14]. La ventaja de utilizar estos CFPE, es que no inducen la reactividad a la prueba de tuberculina, por tanto, no interfieren con las 
pruebas diagnósticas y la efectividad de la vacuna no se ve afectada por la previa sensibilización por micobacterias ambientales [15].

Por otro lado, los antígenos específicos que evocan la inmunidad protectora de los linfocitos Th1 aún no son completamente conocidos; sin embargo, se ha observado que las micobacterias vivas son más eficientes en la generación de la resistencia adquirida específica, comparada con preparaciones de micobacterias muertas; esta observación se ha utilizado como argumento para sostener que los antígenos secretados presentes en los CFPE, producidos por el metabolismo activo bacteriano, son esenciales para tal efecto. Existe pues, clara evidencia de que los antígenos del CFPE son fuertemente reconocidos durante la infección por micobacterias en bovinos naturalmente infectados y en modelos animales; y que varias de las proteínas que los constituyen evocan una respuesta significativa en las fases tempranas de la enfermedad [16]. Dos de los antígenos presentes y ampliamente estudiados en el CFPE de M. bovis son las proteínas DipZ y el complejo de 45-47 kDa. El primero de ellos involucrado en la biogénesis de la enzima citocromo-C oxidasa de la bacteria, y el segundo es un complejo glicoprotéico con capacidad para unirse a la fibronectina, del cual, se dice, puede inducir inmunidad celular en animales infectados [17]. Actualmente los estudios de vacunación contra la tuberculosis se han enfocado en la proteína HspX ( $\alpha$-cristalina) de 16-kDa codificada en el gen Rv2031c, la cual se expresa en bacterias del Complejo $M$. tuberculosis bajo condiciones de hipoxia. La producción de la proteína se incrementa durante la latencia de la bacteria y decrece cuando esta regresa a su crecimiento exponencial, por lo tanto, este antígeno es un posible biomarcador en la identificación de tuberculosis latente, y se ha considerado un candidato importante para producir una vacuna de subunidades con el propósito de prevenir la reactivación de la infección tuberculosa latente. Considerando también para el efecto los factores promotores de la reanimación, las proteínas de Dormancy of survival regulon (DosR) y las proteínas estimulantes de la inanición son candidatos potenciales para el desarrollo de vacunas de subunidades contra la infección de TB. Debido a que esta proteína es producida también por M. bovis su potencial inmunogénico para el control de la TBb se ha considerado [18] y [19].

Mayormente, se ha informado que el tipo de respuesta inmune depende del antígeno involucrado, la micobacteria y, en consecuencia, la resolución de la enfermedad o en caso contrario su desarrollo (patogénesis). La vacunación contra la TBb se considera la mejor opción para el control de la enfermedad, sobre todo en zonas donde las prevalencias o incidencias son altas y en las cuales no se cuenta con los recursos para costear programas tradicionales de prevención, control y erradicación. El objetivo de este trabajo fue evaluar la eficacia de la BCG y del CFPE de M. bovis 
como inmunógenos contra la TBb, a través del monitoreo del IFN- $\gamma$, evaluación de citocinas Th1 (IFN- $\gamma, I L-2)$, Th2 (IL-4, IL-10) y presencia de lesiones macroscópicas a la necropsia tras el desafío.

\section{Materiales y métodos}

\section{Declaración de ética}

El diseño del estudio, metodología del muestreo, desafió y sacrificio fueron evaluados y aprobados por el Comité de Bioética para el Cuidado y Uso de Animales para Experimentación en Proyectos de Investigación del Centro de Sanidad Animal e Inocuidad (CENID-SAI) del Instituto Nacional de Investigación Forestal, Agrícola y Pecuaria (INIFAP). La recolección de muestras de sangre y la administración de la Prueba Intradérmica de la Tuberculina Comparativa (PITC) fueron realizadas por veterinarios calificados, siguiendo los procedimientos oficiales de la Norma Oficial Mexicana (NOM-041-ZOO 1995) de la Campaña Nacional contra la tuberculosis.

\section{Diseño experimental}

Se utilizaron 24 hembras de la raza Holstein-Fresian de 6 meses de edad, procedentes de una zona libre de TBb, previa confirmación de su negatividad a la Prueba Cervical Comparativa (PPC), interferón gama (IFN- $\gamma$ ) inmunoensayo (ELISA) y la reacción en cadena de la polimerasa (PCR), a partir de muestras de moco nasal.

Los animales fueron divididos en 4 grupos (6 animales/grupo), tal y como se describe a continuación: 1) grupo control inoculado con solución de fosfatos estéril

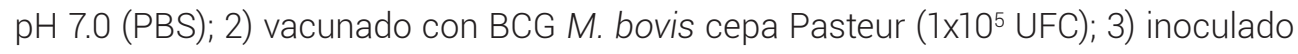
con $300 \mu \mathrm{g}$ de CFPE de M. bovis AN5 y 4) al cual se les administró dos días antes 200 ng de IFN- $\gamma$ bovino recombinante antes de ser inmunizados también con $300 \mu \mathrm{g}$ de CFPE. Las vacunas se aplicaron en la tabla de cuello por vía intradérmica, y 21 días después se hizo la revacunación bajo el mismo esquema, pero sin la aplicación del IFN- $\gamma$ bovino recombinante.

Para la evaluación de citocinas, se establecieron 3 muestreos en diferentes tiempos: antes de la vacunación (tiempo 0); 3 meses posvacunación y 6 meses posdesafío.

En la PCC se utilizaron las tuberculinas autorizadas para efectos de la Campaña Nacional contra la Tuberculosis y Brucelosis (CANATB), bajo la Norma Oficial Mexicana NOM-031-ZOO [20]. 
8 Evaluación experimental de vacuna BCG y extracto proteico en bovinos, vía expresión de citocinas

\section{Producción de IFN- $\gamma$}

La prueba de IFN- $\boldsymbol{\gamma}$, mejor conocida como Bovigam (BOVIGAM ${ }^{\mathrm{TM}}$ Bovine Gamma Interferón Test), se aplicó al inicio del experimento para diagnosticar y posteriormente para el monitoreo de la respuesta inmune celular empleando para el efecto el PPD bovino y el PPD aviar, incluidos en el sistema comercial, así como las proteínas del complejo antigénico 45/47 kDa o APA (antígeno rico en prolina y alanina) y la proteína de biogénesis de la citocromo tipo C, proteína integral de membrana DipZ (DipZ). Luego se distribuyó la sangre heparinizada de los animales de estudio en placas de 24 pozos para cultivo celular (NUNCLON ${ }^{\text {TM }}$ Delta, NUNC®), a razón de 1,5 ml de sangre/ pozo en los pozos correspondientes para cada uno de los antígenos a evaluar y para el mitógeno Concanavalina A (ConA), dejando un pozo sin estímulo como control.

Las placas se incubaron por $24 \mathrm{~h}$, a $37^{\circ} \mathrm{C}$, en una atmósfera de aire enriquecida con $5 \%$ de $\mathrm{CO}_{2 y} 95 \%$ de humedad relativa. Los plasmas de los diferentes cultivos de sangre se colectaron y mantuvieron a $-70^{\circ} \mathrm{C}$ hasta su evaluación. El IFN- $\gamma$ liberado o producido ante el estímulo antigénico se cuantificó de acuerdo con las especificaciones del sistema comercial, para cuyos efectos se empleó un ensayo inmunoenzimático tipo sándwich. Se depositaron $50 \mu \mathrm{l} /$ pozo de los plasmas colectados diluidos 1:2 por duplicado en los pozos correspondientes de las placas de ELISA recubiertas con el anticuerpo monoclonal de captura anti-IFN- $\gamma$ bovino.

Posteriormente, las placas de ELISA se incubaron a temperatura ambiente (TA) por 1 h y se lavaron cinco veces con PBS-Tween 20 al 0,05\%. Después de este procedimiento se adicionaron $100 \mu \mathrm{l}$ del conjugado (anticuerpo de detección, anti IFN- $\gamma$ bovino marcado con peroxidasa) y se incubó por $1 \mathrm{~h}$. A continuación, se efectuó un ciclo de lavados para luego adicionar el sustrato 3,3',5,5' tetrametilbencidina (TMB), la reacción se detuvo por la adición de la solución de paro $\left(\mathrm{H}_{2} \mathrm{SO}_{4} 0.5 \mathrm{M}\right)$. Las concentraciones relativas de IFN- $\gamma$ se registraron como la densidad óptica (DO) medida a $450 \mathrm{~nm}$. Los resultados de la prueba de BOVIGAM como método diagnóstico se calcularon considerando la diferencia entre el valor de las $\mathrm{DO}_{450}$, obtenida de la muestra estimulada con el PPD bovino, menos el valor de la muestra sin estimular, la cual debe ser > a 0,5, siempre y cuando la diferencia entre el valor de la muestra obtenido con el PPD bovino y el de la muestra estimulada con el PPD aviar sea igual a 0,5 [21]. Los valores obtenidos para monitoreo de la respuesta inmune fueron graficados calculando el valor promedio de los animales de cada grupo con los diferentes antígenos. 
Maura Cruz-Fierro, Laura Jaramillo-Meza, Clara Inés Espitia-Pinzón, Rafael Pérez-González, 9 Anabelle Manzo-Sandoval, Fernando Díaz-Otero

\section{ELISA comparativa}

Para la evaluación de la inmunidad humoral, se recubrieron placas con los CFPE de

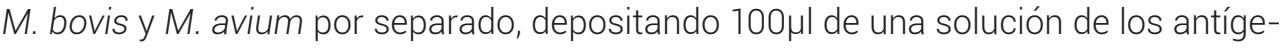
nos $(10 \mu \mathrm{g} / 1 \mathrm{ml}$ ) en buffer de pegado (amortiguador de carbonatos pH 9.6) por pozo. Se incubó por 12 h a TA y se eliminó la solución. Se lavó 5 veces con solución de lavado (PBS-Tween 20 al 0.05 \%). Se añadieron $100 \mu$ le solución de bloqueo con 3 \% de leche descremada en solución de lavado, incubando por 1 h a $37^{\circ} \mathrm{C}$, y nuevamente recibieron un ciclo de lavado. Se añadieron $100 \mu \mathrm{l}$ de cada suero problema diluido 1:100 en solución bloqueadora e incubaron 1 h a TA. Luego de otro ciclo de lavados se agregaron $100 \mu \mathrm{l}$ de proteína G-peroxidasa diluida 1: 10000 en solución bloqueadora, se dejaron incubar $1 \mathrm{~h}$ a $37^{\circ} \mathrm{C}$ y se lavaron 5 veces. Inmediatamente se añadieron $100 \mu \mathrm{l} /$ pozo de solución de revelado (10 ml/placa de amortiguador de citrato-fosfato $\mathrm{pH}$ 4.5, $4 \mu \mathrm{g}$ de orto-fenilendiamina y $4 \mu \mathrm{l} \mathrm{de} \mathrm{H}_{2} \mathrm{O}_{2}$ ). La reacción se detuvo a los $15 \mathrm{~min}$ con $50 \mu \mathrm{l}$ de solución de paro $\left(\mathrm{H}_{2} \mathrm{SO}_{4} 2 \mathrm{M}\right)$. Las lecturas se realizaron a $492 \mathrm{~nm}$ [22].

\section{Prueba de PCR}

Para el diagnóstico de TBb por reacción en cadena de la polimerasa (PCR), se extrajo el DNA de cada muestra de exudado nasal mediante el método de Van Soolingen, et al., [23]. El DNA se disolvió en $20 \mu \mathrm{l}$ de agua milli Q y almacenó a - $20{ }^{\circ} \mathrm{C}$ hasta su empleo. Para la PCR se empleó como control positivo, DNA de M. tuberculosis H37Rv y DNA de M. bovis AN5, como control negativo DNA de M. avium DN4 y agua Milli-Q. Se siguió esencialmente el método descrito por Cousins, et al., [24]. Los iniciadores para la PCR fueron TB1a 5’ CTC GTC CAG CGC CGC TTC GG 3’ y el TB1b 5’CCT GCG AGC GTA GGG GTC GC 3', que amplifican el gen MPB70 con un tamaño de 372 pb, que identifica al complejo M. tuberculosis. La reacción se llevó a cabo en un volumen final de $50 \mu \mathrm{l}$ con las concentraciones de: dNTP's 10 mM, Mg 2 Cl 1.5 mM, 20 pM de cada primer, $0.625 \mathrm{U}$ de Taq polimerasa y $100 \mathrm{ng}$ de DNA de cada muestra. Se amplificó por 30 ciclos: $1^{\prime} 96^{\circ} \mathrm{C}, 1^{\prime} 55^{\circ} \mathrm{C}$ y $1^{\prime} 72^{\circ} \mathrm{C}$. Los productos se visualizaron en geles de agarosa al 1,5\% teñidos con bromuro de etidio (BrEt) al $1 \%$.

\section{Cultivo de células mononucleares de sangre periférica (PBMC)}

Para la evaluación de citocinas se trabajó con PBMC, estas se separaron por gradiente con Ficoll-Paque Plus por centrifugación a 2800 rpm por 30 min. Se recuperó la interface de leucocitos y adicionó solución de Hanks para lavado, luego de lo cual se 
centrifugaron nuevamente a 2800 rpm por 10 min. Se adicionó RPMI 1640 con suero fetal bovino (FBS) al 10 \%. La suspensión celular se ajustó a 5×106 células/pozo. Los cultivos se estimularon con $100 \mu \mathrm{l}$ de PPD bovino $(300 \mu \mathrm{g} / \mathrm{ml}), 100 \mu \mathrm{l}$ de PPD aviar (300 $\mu \mathrm{g} / \mathrm{ml}), 2.5 \mu \mathrm{l}$ del complejo 45-47 kDa (125 $\mu \mathrm{g} / \mathrm{ml}), 2.5 \mu \mathrm{l}$ del antígeno DipZ (125 $\mu \mathrm{g} / \mathrm{ml}), 10 \mu \mathrm{l}$ de ConA (0.2 mg/ml) y se dejó un pozo sin estímulo. Se incubaron por $72 \mathrm{~h}$ a $37{ }^{\circ} \mathrm{C}$ al $5 \%$ de $\mathrm{CO}_{2}$. Se cosecharon $200 \mu \mathrm{l}$ de sobrenadante para realizar la prueba de IFN- $\gamma$.

\section{Aislamiento de RNA total}

Los cultivos de PBMC se recuperaron y se centrifugaron a 4000 rpm por 5 min a $4{ }^{\circ} \mathrm{C}$, se adicionó $1 \mathrm{ml}$ de Trizol y se congelaron a $-70{ }^{\circ} \mathrm{C}$ [25]. El RNA se extrajo con $200 \mu$ l de cloroformo-isoamílico, se centrifugó y se recuperó la fase acuosa. El RNA se precipitó con $500 \mu \mathrm{l}$ de isopropanol. La pastilla se lavó con etanol al $100 \%$ y posteriormente se realizó un segundo lavado con etanol al 75 \% frío, el RNA fue resuspendido en $20 \mu \mathrm{l}$ de agua DEPC, se calentó al baño de María a $60{ }^{\circ} \mathrm{C}$ por $10 \mathrm{~min}$ y se determinó la concentración empleando el Gene Quant (RNA/DNA calculator) [26].

\section{Evaluación de citocinas por RT-PCR}

A partir del RNA total aislado de cada muestra se sintetizó el cDNA. Las reacciones de RT se realizaron en $40 \mu$ l, la mezcla contenía $2 \mu$ de Oligo $d(T) 1 \mu \mathrm{g}, 4 \mu \mathrm{l}$ de $5 \mathrm{X}$ Fisrt-Strand Buffer (50 mM Tris- $\mathrm{HCl}, \mathrm{pH} 8.3,7 \mathrm{mM} \mathrm{MgCl}_{2}, 40 \mathrm{mM} \mathrm{KCl}, 10 \mathrm{mM}$ DTT); $4 \mu \mathrm{l}$ de mezcla de desoxiribonucleótidos (dNTP: dGTP, dATP, dTTP, dCTP) 10 mM ( $1 \mu$ l de cada uno), $2 \mu$ l de RNAse Inhibitor $40 \mathrm{U}, 2 \mu$ l de la enzima M-MLV Reverse Transcriptase y $250 \mu \mathrm{g}$ de RNA total. La mezcla se sometió a un ciclo de RT a $70{ }^{\circ} \mathrm{C}$ por $3 \mathrm{~min}, 37^{\circ} \mathrm{C}$ por $60 \mathrm{~min}$ y $70^{\circ} \mathrm{C}$ por $15 \mathrm{~min}$.

El cDNA sintetizado se agregó a las reacciones de PCR que se llevaron a cabo en un volumen final de $25 \mu \mathrm{l}$. La mezcla fue $2.5 \mu \mathrm{l}$ de amortiguador de reacción 10X (KCl 500 mM, Tris-HCl pH 8.3100 mM, gelatina $10 \mu \mathrm{g} / \mathrm{ml}), 1.5 \mu \mathrm{l}$ de $\mathrm{MgCl}_{2} 20 \mathrm{X}(1.5$ mM), $0.5 \mu$ l de desoxiribonucleótidos (dNTP: dGTP, dATP, dTTP, dCTP) (1:1:1:1) 10 mM, $0.5 \mu$ l de cada primer (10 pmol), $0.12 \mu$ l de Amplificasa ADN Polimerasa Termoestable (0.6 U), $4.5 \mu$ l de cada cDNA y agua DEPC cbp $25 \mu \mathrm{l}$ [27].

Las reacciones de PCR se desarrollaron en un termociclador iClicler de acuerdo con las condiciones establecidas previamente para cada citocina (tabla 1). Los resultados de RT-PCR, con la $\beta$-actina normalizada para la expresión de las citocinas, fueron representados como la intensidad relativa de las bandas encontradas en los geles de agarosa teñidos con BrEt utilizando el software LabWorks 4.0 [28]. 
Maura Cruz-Fierro, Laura Jaramillo-Meza, Clara Inés Espitia-Pinzón, Rafael Pérez-González, 11 Anabelle Manzo-Sandoval, Fernando Díaz-Otero

Tabla 1. Secuencia de los iniciadores utilizados, tamaño del fragmento amplificado para las diferentes citocinas de origen bovino y programas empleados

\begin{tabular}{|c|c|c|}
\hline $\begin{array}{c}\text { Nombre de la citocina } \\
\text { Referencia } \\
\text { Bibliográfica }\end{array}$ & Secuencia de los iniciadores & $\begin{array}{c}\text { Tamaño del fragmento } \\
\text { amplificado cDNA (pb) y } \\
\text { Programa de Termociclador }\end{array}$ \\
\hline & & $457 \mathrm{pb}$ \\
\hline $\mathrm{IL}-2$ & 5’ AGA TAC AAC TCT TGT CTT GC3' & $95^{\circ} \mathrm{C} 94^{\circ} \mathrm{C} 52^{\circ} \mathrm{C} 72^{\circ} \mathrm{C} 72^{\circ} \mathrm{C}$ \\
\hline \multirow[t]{3}{*}{ Cerreti et al., 1986a } & 5' AGT CAT TGT TGA GTA GAT GC3' & 4' $30^{\prime \prime} 45^{\prime \prime} 1^{\prime} 5^{\prime}$ \\
\hline & & 30 CICLOS \\
\hline & & $184 \mathrm{pb}$ \\
\hline INF- $\gamma$ & 5' TTC AGA GCC AAA TTG TCT CC 3' & $95^{\circ} \mathrm{C} 94^{\circ} \mathrm{C} 53^{\circ} \mathrm{C} 72^{\circ} \mathrm{C} 72^{\circ} \mathrm{C}$ \\
\hline \multirow[t]{3}{*}{ Cerreti et al., 1986b } & 5' CTG GAT CTG CAG ATC ATC CA 3' & $4^{\prime} \quad 1^{\prime} \quad 1^{\prime} 1^{\prime} 30^{\prime \prime} 7$ \\
\hline & & 31 CICLOS \\
\hline & & $311 \mathrm{pb}$ \\
\hline IL-4 & 5' CTA TTA ATG GGT CTC ACC TAC CA3' & $94^{\circ} \mathrm{C} 94^{\circ} 51^{\circ} \mathrm{C} 72^{\circ} \mathrm{C} 72^{\circ} \mathrm{C}$ \\
\hline \multirow[t]{3}{*}{ Heussier et al., 1992} & 3’ CTT GCC AAG CTG TTG AGA TTC 5' & $5^{\prime} 30^{\prime \prime} 45^{\prime \prime} 1^{\prime} 5^{\prime}$ \\
\hline & & 33 CICLOS \\
\hline & & 471 \\
\hline IL-10 & 5’ GTT GCC TGG TCT TCC TGG CTG3' & $95^{\circ} \mathrm{C} 94^{\circ} \mathrm{C} 53^{\circ} \mathrm{C} 72^{\circ} \mathrm{C} 72^{\circ} \mathrm{C}$ \\
\hline \multirow[t]{3}{*}{ Degen et al., 1983} & 5’ TAT GTA GTT GAT GAA GAT GTC3' & $4^{\prime} 1^{\prime} 1^{\prime} 1^{\prime} 30^{\prime \prime} 7^{\prime}$ \\
\hline & & 30 CICLOS \\
\hline & & $890 \mathrm{pb}$ \\
\hline$\beta$-actina & 5' ACC AAC TGG GAC GAC ATG GAG 3' & $94^{\circ} \mathrm{C} 94^{\circ} \mathrm{C} 52^{\circ} \mathrm{C} 72^{\circ} \mathrm{C} 72^{\circ} \mathrm{C}$ \\
\hline \multirow[t]{2}{*}{ Deguen et al., 1983} & 3' GCA TTT GCG GTG GAC AAT GGA 5' & $5^{\prime} 50^{\prime \prime} 50^{\prime \prime} 1^{\prime} 10^{\prime \prime} 10^{\prime}$ \\
\hline & & 30 CICLOS \\
\hline
\end{tabular}

Fuente: elaboración propia

\section{Cepa de desafío}

Se utilizó un aislado de M. bovis obtenido de un caso de TBb, identificado como cepa N 9930. Esta última se cultivó en agar Middlebrook enriquecido con $10 \%$ de Oleic Albumin Dextrose Catalase (OADC), a partir del cual se seleccionaron de 3 a 5 colonias con morfologías semejantes para su propagación en caldo Middlebrook $7 \mathrm{H} 9$ con $1 \%$ de OADC y $0.5 \mathrm{~g} / \mathrm{l}$ de Tween 80; posteriormente se incubó por 8 días, el cultivo se transfirió a un volumen de $135 \mathrm{ml}$ de medio fresco por 11 días más, hasta su fase logarítmica.

Para la cuantificación de las UFC, se tomó una alícuota y se realizaron diluciones decimales, de las cuales se tomaron alícuotas para sembrarlas en agar $7 \mathrm{H} 11$ a partir de la dilución $10^{-3}-10^{-5}$ por triplicado, luego se incubaron por un periodo de 3 a 
4 semanas, a $37^{\circ} \mathrm{C}$, y se ajustaron a $10^{4} \mathrm{UFC} / \mathrm{ml}$. Todos los grupos fueron desafiados vía intratraqueal a los 6 meses posvacunación y se sacrificaron 6 meses posdesafío.

\section{Criterios de evaluación de lesiones (post mortem)}

Se colectaron los linfonodos (LN) de cabeza (submandibular, retrofaríngeos y parótidos) y de tórax (mediastínicos y bronquiales). Las lesiones a nivel macroscópico, tanto de LN como pulmonares, fueron calificadas con un sistema de cruces de acuerdo con su tamaño. Se asignó (+) a las lesiones de $\geq 0,2 \mathrm{~cm}$ y $\leq 0,5 \mathrm{~cm}$ de diámetro, $(++)$ a las lesiones de $>0,5 \mathrm{~cm}$ y $<1,0 \mathrm{~cm}$ y $(+++)$ a las lesiones $>1,0 \mathrm{~cm}$. Se establecieron tres grados de severidad de acuerdo con su tamaño y gravedad de la patología macroscópica observada, calificándose como: leves, cuando los focos eran pequeños y circunscritos con lesiones visibles; moderadas, cuando las lesiones menores de $1 \mathrm{~cm}$ presentaban focos necróticos y/o piogranulomatosas, y severas, cuando las lesiones eran extensas y de diferentes tamaños (mayores a $1 \mathrm{~cm}$ ), confluentes, constituidas por centros de necrosis licuefactiva, y de diferente grado de mineralización rodeadas por tejido conectivo. Las lesiones fueron clasificadas siguiendo metodologías reportadas [29].

\section{Análisis estadístico}

Los datos fueron analizados con el programa STATISTICA versión 5.5. Se realizó un análisis de varianza, seguido de una prueba de Tukey para diferente tamaño de muestra, utilizando la comparación múltiple de medias con un nivel de significancia $(P<0.05)$, para la determinación de posibles diferencias estadísticamente significantes.

\section{Resultados}

\section{Pruebas de PCC, IFN- $\gamma$, ELISA y PCR}

Para su inclusión en el estudio, se evaluó cada uno de los animales con las diferentes pruebas inmunodiagnósticas señaladas y con la prueba de PCR para la detección de bacterias del Complejo M. tuberculosis. Todos los animales resultaron negativos a las diferentes pruebas diagnósticas realizadas. La figura 1 corresponde a la PCR para la detección de M. bovis en muestras de moco nasal de los animales de estudio. En el carril 6 se observa una muestra negativa con sus respectivos controles. 
Maura Cruz-Fierro, Laura Jaramillo-Meza, Clara Inés Espitia-Pinzón, Rafael Pérez-González, 13 Anabelle Manzo-Sandoval, Fernando Díaz-Otero

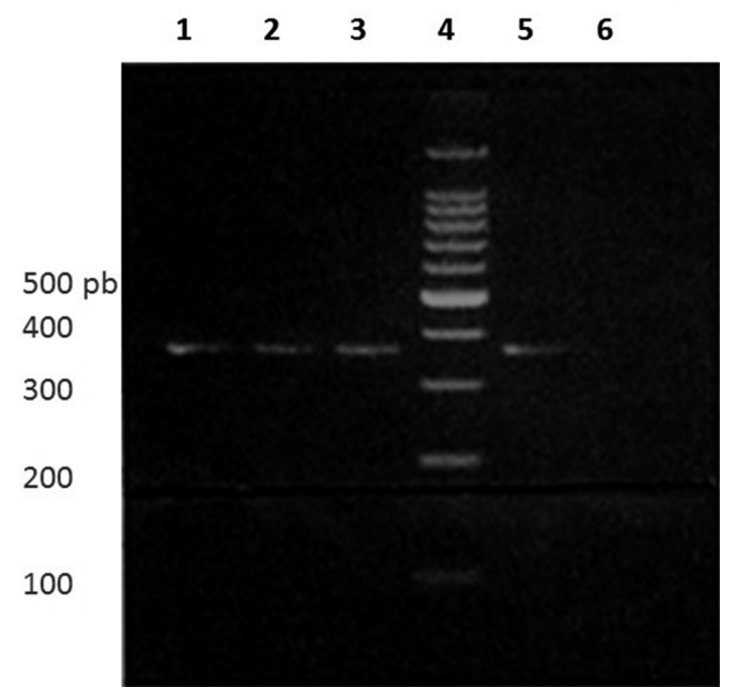

Figura 1. Productos de amplificación de 372 pb del gen de la proteína MPB70 de M. bovis con TB1-a y TB1-b. Carril 1, M. bovis AN5; carril 2, M. tuberculosis H37Rv; carril 3 y 5, DNA de animales infectados con M. bovis; carril 4, marcador de peso molecular, carril 6 de animal negativo a la PCR simple de moco nasal al inicio del experimento

\section{Ensayo de IFN- $\gamma$}

Se evaluó la producción de IFN- $\gamma$ al inicio del experimento (tiempo 0), a los 3 meses (posvacunación) y a los 6 meses (posdesafío) en los diferentes grupos. Al tiempo 0 no hubo diferencia significativa entre grupos con los diferentes antígenos, y la respuesta al mitógeno ConA para los animales de todos los grupos fue altamente significativo, lo cual confirma que el estado inmunológico de todos los animales se encontraba en condiciones óptimas. El mismo comportamiento hacia el mitógeno se observó en todos los grupos a los 3 meses posvacunación, empero, existió una disminución en los niveles de producción con respecto al tiempo 0, la cual fue aún menor para el grupo vacunado con BCG. A los 3 meses posvacunación, la producción de IFN- $\gamma$ con los diferentes antígenos no fue significativa, en realidad los valores fueron bajos para todos los grupos. Se podría señalar, no obstante, que en el grupo inmunizado con BCG la producción con el PPD bovino fue 2 veces mayor que con los otros antígenos a los tres meses posvacunación. A los 6 meses posdesafío la producción de la citocina fue significativa para los diferentes grupos inmunizados en presencia del PPD bovino, y con los antígenos Dipz y el complejo 45-47, siendo mayor la producción para este último, incluyendo al grupo control (Figura 2). 


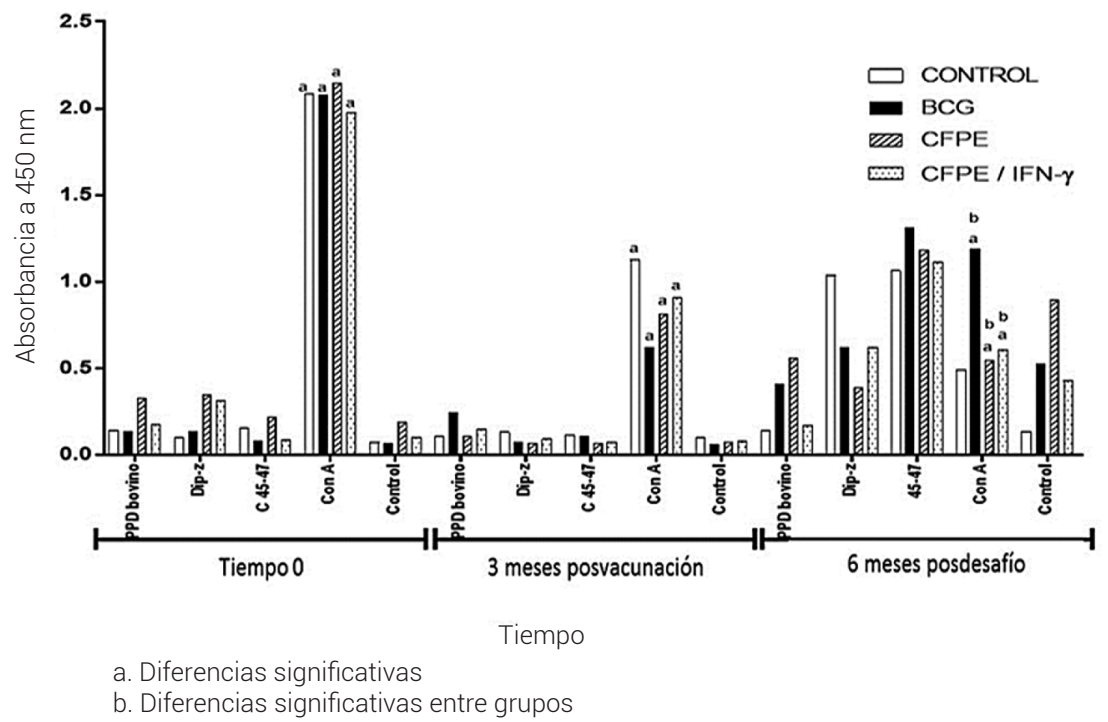

Figura 2. Resultados de la producción de IFN-y en cultivos de sangre completa estimulados con los diferentes antígenos evaluados (PPD bovino, DipZ, C-45-47) y el mitógeno ConA, al tiempo 0 , tres meses posvacunación y seis meses posdesafió para los grupos vacunados con BCG, CFPE, CFPE+IFN- $\gamma$, y el grupo control.

\section{Expresión de citocinas por RT-PCR}

Los valores de expresión de las diferentes citocinas se calcularon considerando la intensidad relativa media con respecto a la expresión de la $\beta$-actina dentro de los animales de cada grupo. En la figura 3 se observan los productos de amplificación de $\beta$-actina (890 pb), en gel de agarosa al 1,5\% teñido con BrEt al $1 \%$, correspondiente a las células sin estimular, utilizadas como control. Los 24 animales mostraron amplificación para este gen constitutivo con diferencias en grado de intensidad.

\section{$\begin{array}{llllllllllllll}1 & 2 & 3 & 4 & 5 & 6 & 7 & 8 & 9 & 10 & 11 & 12 & \mathrm{PM}\end{array}$}

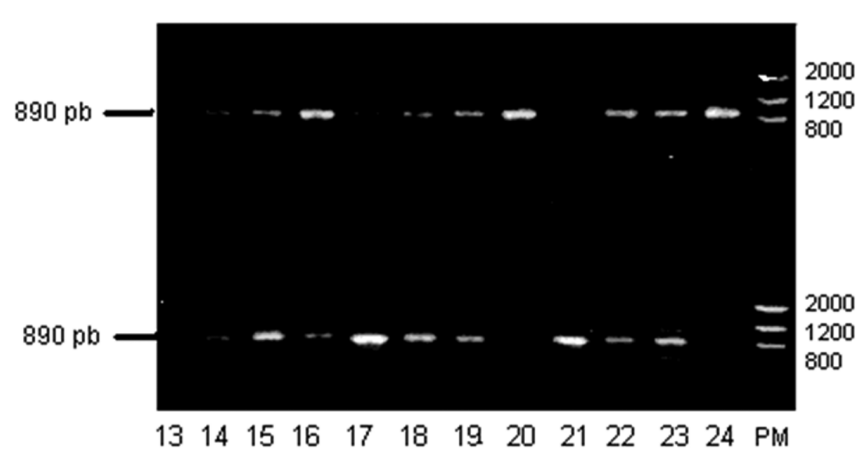

Figura 3. Electroforesis en gel de agarosa al 1,5\% de los productos amplificados para el gen de la $\beta$-actina ( $890 \mathrm{pb}$ ) por RT-PCR, obtenidos de los cultivos de PMNC de los diferentes animales sin estimular, carriles 1-24. Carriles PM marcadores de peso molecular. 
En la figura 4 se muestran los productos de amplificación del IFN- $\gamma(184$ pb), en comparación con la $\beta$-actina (890 pb) con los diferentes antígenos micobacterianos y el mitógeno en muestras de dos animales del grupo vacunado con BCG durante el segundo muestreo, estimulados con los diferentes antígenos.

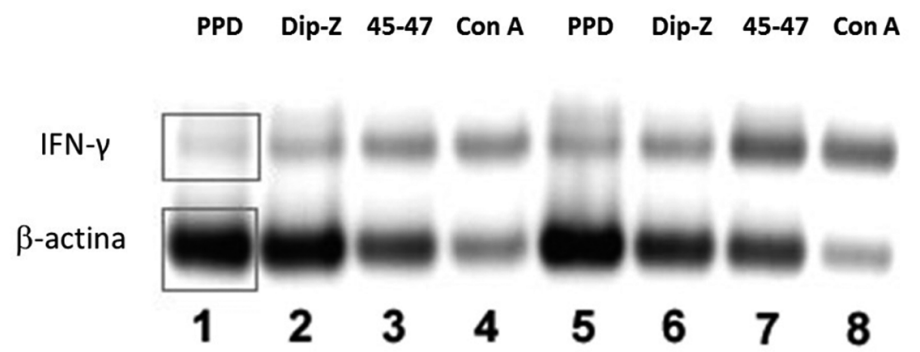

Figura 4. Análisis de la intensidad de expresión de los genes de IFN- $\gamma$ y $\beta$-actina por RT-PCR. La expresión se cuantificó mediante el software Labworks 4, comparando la intensidad de las bandas encontradas en los geles de agarosa teñidos con BrEt con la intensidad de las bandas de $\beta$-actina. Los números del 1-8 ejemplifican (carril 1-4 animal 1, carril 5-8 animal 2), pertenecientes al grupo vacunado con BCG a los tres meses posvacunación.

En la figura 5 se observan los productos de amplificación del gen de la $\beta$-actina (890 pb), IFN- $\gamma$ (184 pb), IL-2 (457 pb), IL-4 (311 pb) e IL-10 (471 pb) de muestras de animales vacunados con BCG, estimulados con diferentes antígenos a los 3 meses posvacunación.

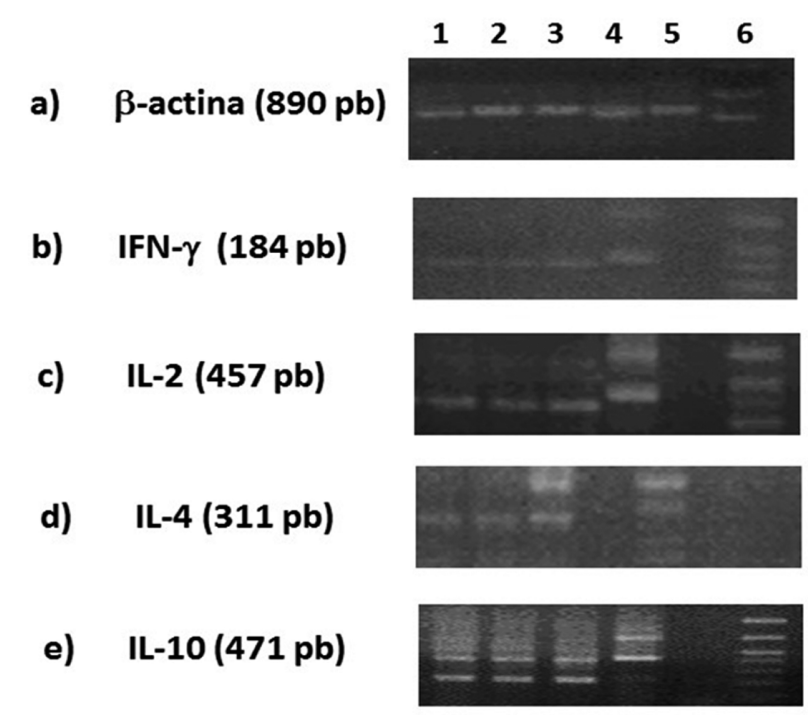

Figura 5. Productos de amplificación de $\beta$-actina (a), IFN- $\gamma$ (b), IL-2 (c), IL-4 (d) e IL-10 (e) de algunos de los animales, en geles de agarosa al 1,5\%, teñidos con BrEt al $1 \%$. Carril 1 , sin estímulo; carril 2, células estimuladas con PPD bovis; carril 3, células estimulas con DipZ; carril 4, células estimuladas con antígeno 45-47; carril 5, células estimuladas con ConA; carril 6, corresponde a marcador de peso molecular. Las muestras se obtuvieron del grupo vacunado con BCG, a los tres meses posvacunación. 


\section{Primer muestreo}

De acuerdo con los análisis determinados por la intensidad de los productos de amplificación para las citocinas evaluadas, se observó que al inicio del experimento la expresión de IFN- $\gamma$ fue significativamente detectable en todos los grupos, aún sin el estímulo antigénico. De manera similar, y aunque no en todos los casos detectable, se observó la expresión de IL-2 en algunos animales en el tiempo previo a la inmunización. En tanto que, la expresión de IL-4 e IL-10 fue insignificante en todos los grupos de estudio (figura 6).

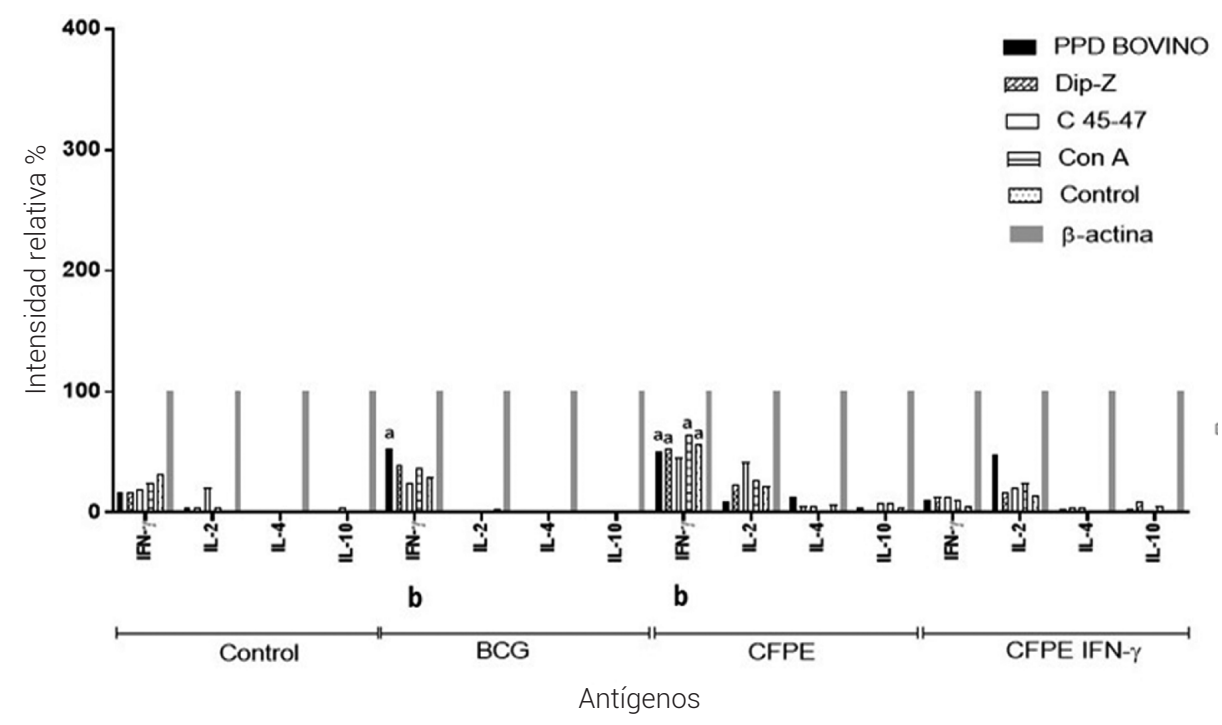

a. Diferencia significativa entre antígenos

b. Diferencia significativa entre citocinas

Figura 6. Resultados del análisis por RT-PCR para los grupos control y vacunados Con BCG, CFPE y CFPE+IFN-p previo a la inmunización. Se observa la expresión promedio de las citocinas estudiadas (IFN- $y$, IL-2, IL-4 e IL-10), con referencia a la $\beta$-actina. Los resultados están representados como la intensidad relativa de las bandas en geles teñidos con BrEt

\section{Segundo muestreo}

A los tres meses posvacunación la expresión del IFN- $\gamma$, en el grupo vacunado con BCG, fue significativamente más alta comparando con los otros grupos inmunizados, tanto en presencia del PPD bovino, como con el antígeno DipZ. La expresión de IL-2 e IL-4 no fue significativa para este grupo, pero sí existieron valores relativos para la IL-10 con respecto a la $\beta$-actina con todos los antígenos empleados. En el 
grupo inmunizado con CFPE+IFN- $\gamma$, la expresión de IL-4 fue significativa con los diferentes antígenos, inclusive en los cultivos de PBMC sin estimular. En este grupo, no hubo expresión de las otras citocinas en este tiempo evaluado (figura 7). En el grupo control sin inmunizar se registraron incrementos relativamente significativos para las diferentes citocinas con el PPD bovino y el mitógeno, lo cual puede deberse a una respuesta inespecífica, a la sensibilización de los animales a microorganismos taxonómicamente relacionados con las micobacterias o bien a micobacterias ambientales, considerando la respuesta observada en el tiempo 0 para los animales de este grupo y la de los otros antes de la inmunización (figura 7 y 8).

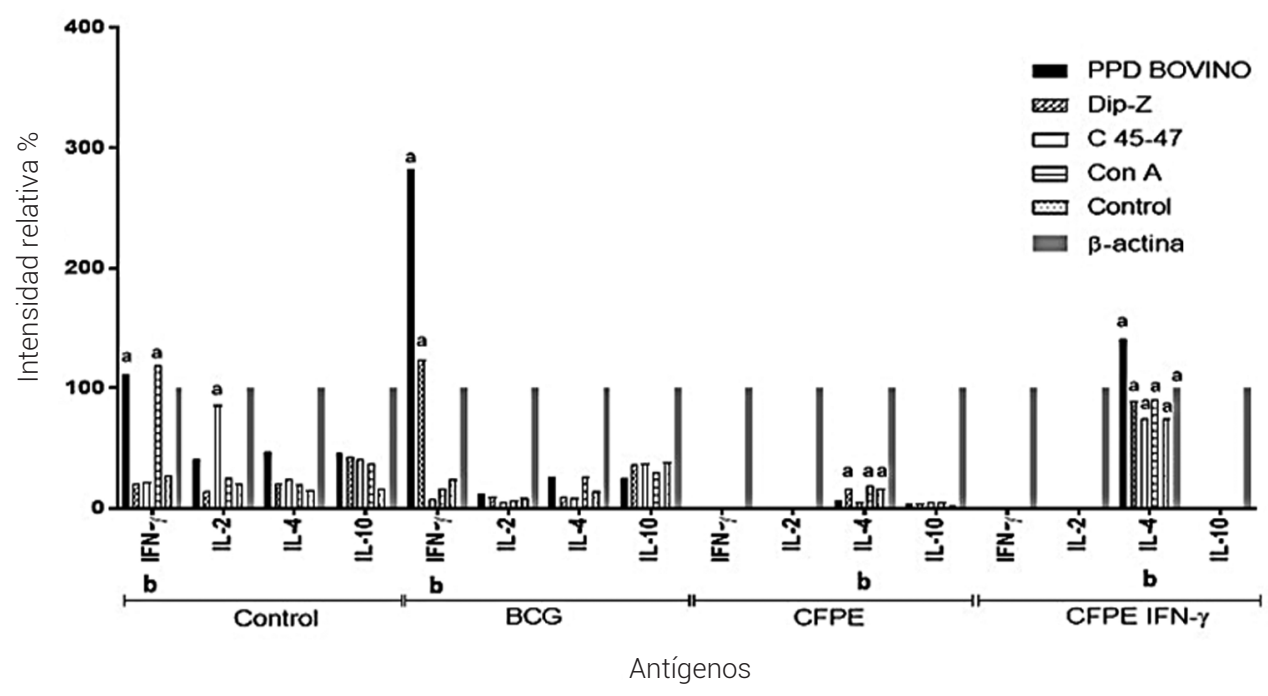

a. Diferencia significativa entre antígenos

b. Diferencia significativa entre citocinas

Figura 7. Resultados de RT-PCR para los grupos control y vacunados con BCG, CFPE y CFPE+IFN- $\gamma$ a los tres meses posvacunación. Se observa la expresión promedio por grupo de las citocinas estudiadas (IFN- $\gamma$, IL-2, IL-4 e IL-10) con relación a la $\beta$-actina. Los resultados están representados como el porcentaje de la intensidad relativa de las bandas en los geles, teñidos con BrEt

\section{Tercer muestreo}

A los seis meses posdesafió, la expresión génica del IFN- $\gamma$ e IL-2 fue significativamente alta en el grupo control, sin incrementarse ante el estímulo antigénico y considerando los índices de expresión relativa que se determinaron en los cultivos de PBMC sin estimular. En este grupo, a diferencia de los resultados observados sobre la expresión de IL-10 a los tres meses posvacunación, en este tiempo posdesafío no 
se registraron niveles de expresión detectables para esta citocina. Con respecto al grupo inmunizado con BCG la expresión de IFN- $\gamma$ e IL-2 e IL-2 fue detectable, pero no mayor a la que se observó en el grupo tratado con IFN- $\gamma$ previo a la inmunización con el CFPE (CFPE+ IFN- $\gamma$ ), el cual mostró una sobreexpresión del gen del IFN- $\gamma$, siendo su expresión 300 veces más alta que la que se registró en el grupo inmunizado con CFPE. Mayormente, para este grupo tratado con IFN- $\gamma$ hubo una alta expresión de IL10, a diferencia de los otros grupos inmunizados y de control. Con respecto a IL-4, su expresión fue significativa en el grupo control y en el grupo tratado con IFN- $\boldsymbol{\gamma}$, pero no para los otros grupos (figura 8).

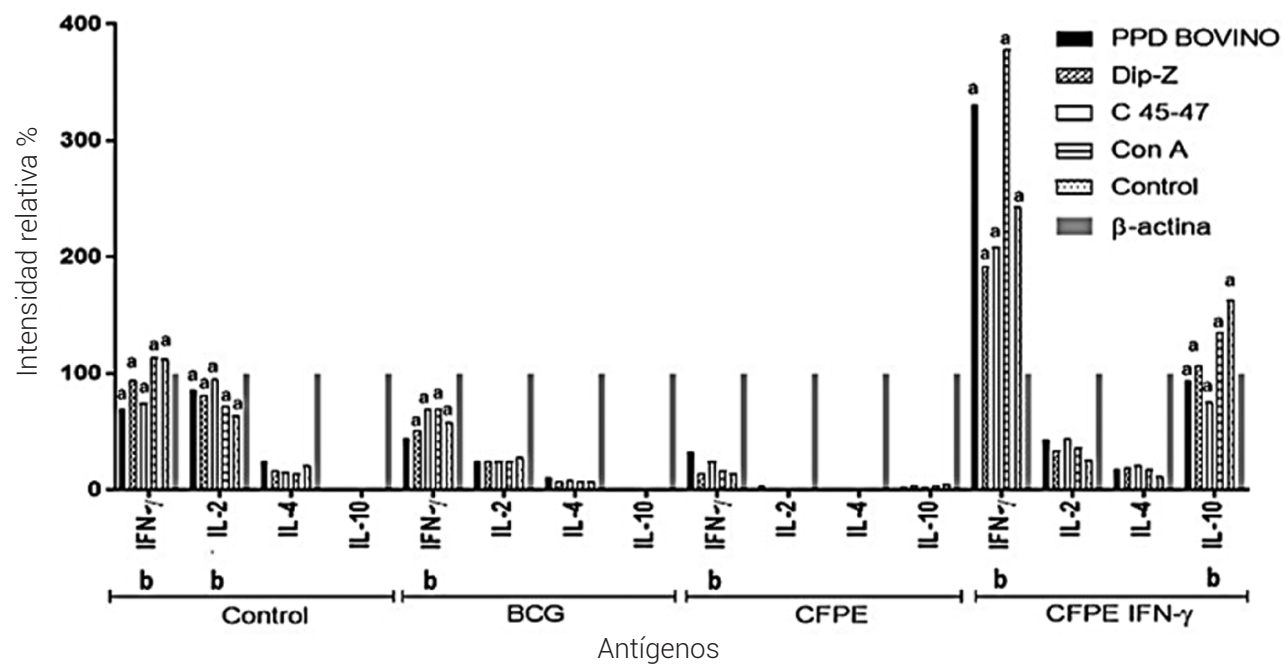

a. Diferencia significativa entre antígenos

b. Diferencia significativa entre citocinas

Figura 8. Resultados de RT-PCR para los grupos control y vacunados con BCG, CFPE y CFPE+IFN $y$ a los seis meses posdesafío. Se observa la expresión promedio por grupo de las citocinas estudiadas (IFN- $\gamma$, IL-2, IL-4 e IL-10), con respecto a $\beta$ - actina. Los resultados están representados como la intensidad relativa de las bandas en los geles teñidos con BrEt

\section{Inspección post mortem}

El grupo control (no vacunado) fue el que mostró el mayor número y severidad de lesiones en todos los animales (6/6). Las lesiones observadas fueron principalmente del tipo de linfadenitis supurativa, siendo los LN cervicales profundos los mayormente afectados; registrándose lesiones mayores a 2,5 cm de diámetro en cuatro de los animales. En tres animales los LN mediastínicos tuvieron lesiones $>0,8 \mathrm{~cm}$ de diámetro. Los $L N$ retrofaríngeos medios de dos animales de este grupo presentaron lesiones 
de $>0,5 \mathrm{~cm}$ a $3 \mathrm{~cm}$. Un solo animal tuvo lesión en LN retrofaríngeos lateral con una lesión > 2,5 cm y otro una lesión en LN mandibular de $1.0 \mathrm{~cm}$, aproximadamente. En el pulmón de un solo animal se observó una lesión $<0,5 \mathrm{~cm}$ de aspecto ligeramente purulento, en el lóbulo caudal derecho.

El grupo 2, vacunado con BCG, fue el que presentó menor número de lesiones y con menor severidad. Tres animales totalmente libres de lesiones (3/6); es decir, un 50 \% con lesiones primordialmente leves: un animal con lesión en la zona de inoculación, un animal con lesión única en LN mediastínicos $<0,7 \mathrm{~cm}$ y otro animal con pequeñas lesiones en LN cervicales profundos y mediastínicos $<0,3 \mathrm{~cm}$. Solamente un animal mostró lesión en los $L N$ retrofaríngeos medios $<1 \mathrm{~cm}$, LN cervicales profundos $>1 \mathrm{~cm}$ y en $L N$ traqueobronquiales y mediastínicos $<1 \mathrm{~cm}$.

Con respecto al grupo 3 , inmunizado con CFPE de M. bovis, las lesiones fueron menos extensas (5/6) con un $83 \%$ de lesiones de linfadenitis supurativas de grado leve en LN, la mayoría de ellas cercanas a la zona de inoculación. Solo un animal estuvo libre de lesiones y tres animales presentaron mínimas lesiones. En cuanto a los LN afectados, se observó que 5 animales tuvieron lesiones en LN cervicales profundos con un diámetro $<0,3 \mathrm{~cm}$ y uno $>1 \mathrm{~cm}$. En 2 animales los $L N$ retrofaríngeos medios presentaron lesiones $<0,5 \mathrm{~cm}$.

En el grupo 4, inmunizados con CFPE + IFN- $\gamma$, solo un animal se encontró libre de lesiones a TBb; sin embargo, comparado con el grupo control, en los animales que sí presentaron lesiones, estas no fueron tan frecuentes, se encontraron localizadas y fueron menos severas (menor tamaño). Los LN más afectados en este grupo fueron los cervicales profundos, encontrando lesiones $<0,2 \mathrm{~cm}$ hasta $>0,1 \mathrm{~cm}$ en cinco animales. Los resultados a la necropsia se muestran detalladamente en la tabla 2.

Tabla 2. Resultados de la necropsia, distribución y severidad de las lesiones macroscópicas en los animales de estudio

\begin{tabular}{|c|c|c|c|c|c|c|c|c|c|}
\hline \multirow{2}{*}{\multicolumn{2}{|c|}{ Grupos }} & \multirow{2}{*}{$\begin{array}{l}\text { Presencia } \\
\text { de lesiones }\end{array}$} & \multicolumn{6}{|c|}{ Grado de severidad } & \multirow{2}{*}{$\begin{array}{c}\text { Nodos linfáticos } \\
\text { más afectados }\end{array}$} \\
\hline & & & $\%$ & * & $\%$ & ** & $\%$ & $\star \star \star$ & \\
\hline \multicolumn{2}{|c|}{ No vacunados } & $6 / 6$ & 100 & $1 / 16$ & 6 & $7 / 16$ & 44 & $8 / 16$ & Cervicales profundos \\
\hline \multirow{3}{*}{ Vacunados } & $B C G$ & $3 / 6$ & 50 & $2 / 7$ & 28 & $4 / 7$ & 57 & $1 / 7$ & Mediastínicos \\
\hline & CFPE & $5 / 6$ & 83 & $9 / 13$ & 69 & $3 / 13$ & 23 & $1 / 13$ & Cervicales profundos \\
\hline & CEPE/INF-y & $5 / 6$ & 83 & $11 / 18$ & 61 & $5 / 18$ & 27 & $2 / 18$ & Cervicales profundos \\
\hline *Leve & & & & \multicolumn{6}{|c|}{ BCG: Bacilo Calmette-Guerin } \\
\hline${ }^{* *}$ Moderado & & & & \multicolumn{6}{|c|}{ CFPE: Extracto proteico de filtrado de cultivo } \\
\hline${ }^{* * \star}$ Severo & & & & \multicolumn{6}{|c|}{ INF- $\gamma$ : Interferón gamma } \\
\hline
\end{tabular}




\section{Discusión}

La vacunación contra la tuberculosis bovina se ha considerado una de las herramientas más viables para reducir los índices de incidencia y prevalencia en los sistemas bovinos de leche. Para las estrategias del progreso de mejores y nuevas vacunas hacia la tuberculosis bovina se parte de identificar aquellos antígenos capaces de estimular y activar linfocitos tipo Th1, que se caracterizan por producir cantidades significativas de IFN- $\gamma$ e IL-2 citocinas que se asocian con la resistencia micobacteriana [15]. En investigaciones previas, mayormente se ha informado sobre la importancia que tiene la edad de los animales al momento de la inmunización contra la tuberculosis, puesto que a edad temprana se ha demostrado que se establece una mejor inmunidad protectora y específica; por lo tanto, entre menor sea la edad a la cual se aplique la vacuna, mayor será el rango de protección. La mayoría de los animales en este estudio tenían una edad alrededor de los seis meses, lo cual pudo tener influencia en los resultados de expresión de las citocinas registrados previo a la inmunización en los diferentes grupos. Por lo que este factor, tiene un valor importante ya que existe un riesgo mayor de infección cuando no se vacunan a edades tempranas, y en consecuencia menor es la protección de la vacuna [30].

Con respecto a la producción de IFN- $\gamma$, no se observaron incrementos significativos en ninguno de los grupos tratados a los tres meses posvacunación; sin embargo, a los seis meses posdesafío, en los cultivos de PBMC obtenidas de los animales del grupo vacunado con BCG, que fueron estimulados con los antígenos del complejo 45-47 se observó en promedio el nivel más alto de producción de la citocina, seguido de los niveles detectados con el antígeno DipZ y con el propio PPD bovino.

A través de la técnica de RT-PCR fueron evaluadas: IFN- $\gamma$ e IL-2, que corresponden a las del patrón Th1 y las del patrón Th2: IL-4 e IL-10, en tres diferentes etapas del estudio, antes de la vacunación, a los tres meses posvacunación y seis meses posdesafío. La expresión del mRNA es una medida apropiada de la producción de citocinas, ya que la mayoría de los genes de las citocinas son regulados a través de la trascripción y su expresión se correlaciona directamente con los niveles de proteína [31]. Esta prueba de RT-PCR, ha sido empleada por algunos investigadores como herramienta para detectar la transcripción de mRNA de citocinas bovinas en PBMC [32].

Los niveles de expresión de IFN- $\boldsymbol{\gamma}$ detectados en el grupo vacunado con BCG correlacionan con un patrón de respuesta inmune orientado hacia una respuesta Th1; Mayormente, se ha indicado que la BCG es un potente estimulador de células CD4+ y un pobre estimulador de células CD8+ [33].

Se ha descrito que la vacuna BCG induce niveles significativos de producción

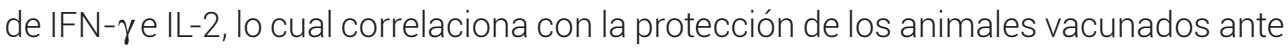


Maura Cruz-Fierro, Laura Jaramillo-Meza, Clara Inés Espitia-Pinzón, Rafael Pérez-González, 21 Anabelle Manzo-Sandoval, Fernando Díaz-Otero

el desafío experimental; ello señala la importancia de estas citocinas para promover la resistencia a la infección [8] [9] y [34]. Sin embargo, también se ha demostrado que el establecimiento de una inmunidad protectora depende de la dosis de vacuna BCG empleada; dosis altas inducen una mayor respuesta inflamatoria en animales vacunados en relación con aquellos en los que se les aplica una dosis baja de vacuna [31]. La dosis de BCG empleada en el estudio está dentro de los rangos de dosis bajas que, de acuerdo con otros autores inducen una mejor respuesta inmune y mejor protección [5] [31] y [35].

Con el uso de la BCG, los bovinos tienen hasta un 75 \% de protección contra la infección experimental intratraqueal con M. bovis [34]. En animales vacunados experimentalmente con BCG, se ha visto protección y un menor desarrollo de lesiones, junto con una menor severidad [35], como ha sido demostrado en el presente estudio. En la inspección post mortem tres animales no presentaron lesión alguna, mientras que los restantes desarrollaron lesiones moderadas.

Respecto al grupo CFPE, la producción de IFN- $\gamma$ y la valoración del patrón de citocinas se correlaciona positivamente con la presencia de lesiones en pocos órganos, y de severidad moderada. Esto sugiere una protección eficaz, en términos del desarrollo y extensión de las lesiones. Se ha observado que el uso de CFPE de M. bovis estimula la respuesta inmune y protege contra la infección; sin embargo, puede estimular la producción de altos niveles de anticuerpos y bajos niveles de citocinas del patrón Th1, por lo que se considera como el segundo candidato vacunal, después de la BCG [36] y [37].

Para el grupo vacunado con CFPE + IFN- $\gamma$, se observó una sobreexpresión de IFN- $\gamma$ en el tiempo posdesafío, que coexistió con una expresión significativa de IL-10, citocina que se ha determinado modula la respuesta inmunitaria protectora frente a patógenos intracelulares al bloquear la producción de citocinas proinflamatorias, como el TNF-a y la citocina IL-12 polarizando la respuesta inmune tipo Th1, al actuar directamente sobre las células presentadoras de antígenos, como los macrófagos y células dendríticas; mayormente, también puede inhibir la fagocitosis y la muerte microbiana al limitar la producción de intermediarios reactivos de oxígeno y nitrógeno en respuesta al IFN- $\boldsymbol{\gamma}$, mecanismos biológicos fundamentales que median la inmunidad contra las infecciones por M. bovis [19] y [28]. Previo al desafío, se determinaron niveles significativos de expresión de IL-4, señalando desde un inicio la modulación negativa de la respuesta inmune celular por la aplicación exógena del IFN- $\gamma$ recombinante. No obstante, la expresión de IL-4 desciende en el periodo posdesafío evaluado. En cuanto a la inspección de los animales después del sacrificio, solo uno no presentó lesiones; en los demás, las lesiones con características de calcificación en los 
órganos afectados se calificaron entre leves y moderadas. La mineralización de las lesiones se detecta 35 días después de ocurrir la infección por M. bovis, cuando los animales han sido vacunados con CFPE [8].

La vacunación con CFPE produjo una protección significativa, ya que las lesiones sugestivas a tuberculosis fueron observadas en LN cercanos a la zona de inoculación, siendo pequeñas y escasas, con tendencia a encapsular las micobacterias, sin mostrar lesiones que se extendieran a otras partes del cuerpo.

En el grupo control la producción y expresión de IFN- $\gamma$ e IL-2 fue notable con los diferentes antígenos evaluados después del desafío, señalando la presencia de una infección activa en los animales de este grupo, que se confirmó por el mayor número y extensión de lesiones observadas a la inspección postmortem.

De acuerdo con los resultados obtenidos en el estudio, en los animales vacunados con BCG se estableció una respuesta inmune celular importante, capaz de contener la infección micobacteriana ante el desafío experimental al que fueron sometidos, observándose en éstos un menor número y extensión de lesiones tuberculosas a la dosis de vacuna empleada, comparando con aquellas que se desarrollaron en los animales sin vacunar, seguido del grupo vacunado con CFPE. Por lo que, es importante considerar a la vacuna BCG como el mejor candidato vacunal para el control de la tuberculosis bovina con ello se reducirían los riesgos de transmisión dentro de los sistemas de producción bovinos, y sobre todo a la población humana. Así, la vacunación con BCG puede ser útil como alternativa o complemento al establecimiento de otras medidas biosanitarias y de biocontención que coadyuven a reducir la prevalencia de la enfermedad en zonas donde la estrategia de control basada en la eliminación de bovinos reactores a la prueba de la tuberculina es incosteable.

\section{Conclusiones}

- Existió un incremento significativo en la producción de IFN- $\gamma$ para el grupo vacunado con BCG antes del desafío, pero no para los grupos vacunados con el CFPE.

- En el grupo tratado con IFN- $\gamma$ recombinante existió una expresión importante de IL-4 en los cultivos estimulados con los diferentes antígenos micobacterianos.

- Durante el periodo posdesafío, la producción y expresión de IFN- $\gamma$ fue significativa para el grupo inmunizado con CFPE y grupo control; mientras 
Maura Cruz-Fierro, Laura Jaramillo-Meza, Clara Inés Espitia-Pinzón, Rafael Pérez-González,

Anabelle Manzo-Sandoval, Fernando Díaz-Otero

que en el grupo tratado con IFN- $\gamma$ fue notable, tanto la expresión de IFN- $\gamma$, como la de IL-10.

- La combinación de CFPE/IFN- $\gamma$ no mostró sinergismo para favorecer una respuesta tipo Th1. De los antígenos empleados en la estimulación in vitro, el PPD bovino indujo una mayor expresión de IFN- $\boldsymbol{\gamma}$, seguido del complejo 45-47 y Dip-z, pero estos a su vez también estimularon la expresión de otras citocinas proinflamatorias.

- La evaluación de la extensión y grado de lesión en los diferentes grupos mostró un menor efecto protector en aquel que recibió el tratamiento previo con IFN- $\gamma$. No obstante, estas fueron menores a las que se desarrollaron en el grupo control.

- El tratamiento previo a la inmunización con IFN- $\gamma$ mostró un efecto adverso en el establecimiento de la inmunidad protectora debido a una modulación negativa en la respuesta inmune.

- Pese a que no fue evidente una producción significativa de IFN- $\gamma$ en los diferentes grupos inmunizados (como indicio del desarrollo de una respuesta inmune celular importante), fue indudable el grado de protección brindado por la vacunación luego del desafío, especialmente en el grupo inmunizado con la vacuna BCG.

- El grupo de animales inmunizado con la vacuna BCG presentó un menor número de lesiones tuberculosas con grado de extensión más pequeñas, seguido por el grupo vacunado con CFPE, y comparado con aquellas que se desarrollaron en los animales sin vacunar.

\section{Agradecimientos}

Al Instituto Nacional de Investigaciones Forestales, Agrícolas y Pecuarias (INIFAP), por el apoyo financiero para la realización del proyecto número SIGI: 14294534013.

\section{Referencias}

[1] World Organization for Animal Health [OIE]. Manual of diagnostic tests and vaccines for terrestrial animals [online]. Paris: OIE; 2006. Bovine tuberculosis. Disponible en: http://www. oie.int/eng/normes/mmanual/A_00054.htm 
Evaluación experimental de vacuna BCG y extracto proteico en bovinos, vía expresión de citocinas

[2] Olea PF, Muwonge A, Perera A, Dean AS, Mumford E, Vindel EE, et al. Zoonotic tuberculosis in human beings caused by Mycobacterium bovis-a call for action. Lancet Infect Dis. 2016; 17 (1): p. 21-5 DOI: 10.1016/S1473-3099(16)30139-6.

[3] Schiller I, Oesch B, Voldermeir HM, Palmer MV, Harris BN, Orloski KA, et al. Bovine tuberculosis; a review of current and emerging diagnostic techniques in view of their relevance for disease control and eradication. Transbound Emerg Dis. 2010; 57 (4): p. 205-20. DOI: 10.1111/ j.1865-1682.2010.01148.x.

[4] Hope JC, Villarreal-Ramos B. Bovine TB and the development of new vaccines. Comp Immul Microbiol Infect Dis. 2008; 31 (2-3): p. 77-100. DOI: 10.1016/j.cimid.2007.07.003.

[5] Murphy D, Corner LA, Gormley E. Adverse reactions to Mycobacterium bovis bacille CalmetteGuérin (BCG) vaccination against tuberculosis in humans, veterinary animals and wildlife species. Tuberculosis. 2008; 88 (4): p. 344-57. DOI: 10.1016/j.tube.2007.11.010.

[6] Sternberg Lewerin S. Tuberculosis and One Health - What is in a Name? Front Vet Sci. 2015; 2: p. 54. DOI:10.3389/fvets.2015.00054

[7] World Organisation for Animal Health (OIE). Eradication of bovine tuberculosis: a One Health issue. Disponible en: https://oiebulletin.com/wp-content/uploads/bulletins/panorama-2019-1-en.pdf

[8] Wedlock DN, Aldwell FE, Vordermeier HM, Hewinson RG, Buddle BM. Protection against bovine tuberculosis induced by oral vaccination of cattle with Mycobacterium bovis BCG is not enhanced by co-administration of mycobacterial protein vaccines. Vet Immunol Immunopathol. 2011; 144 (3-4): p. 220-7. DOI: 10.1016/j.vetimm.2011.09.005.

[9] Buddle BM, Wilson T, Aldwell FE, de Lisle GW, Vordermeier HM, Hewinson RG, Wedlock DN. Low oral BCG doses fail to protect cattle against an experimental challenge with Mycobacterium bovis. Tuberculosis. 2011; 91(5): p. 400-5. DOI: 10.1016/j.tube.2011.07.001.

[10] Skinner MA, Wedlock DN, Buddle BM. Vaccination of animals against Mycobacterium bovis. Rev. Sci. Tech. 2011; 20 (1): p. 112-32. DOI: 10.20506/rst.20.1.1276.

[11] World Health Organization. WHO statement on BCG revaccination for the prevention of tuberculosis. Bull WHO. 1995; 73 (6): p. 805-6. Disponible en: http://www.who.int/iris/ handle/10665/47934. 
Maura Cruz-Fierro, Laura Jaramillo-Meza, Clara Inés Espitia-Pinzón, Rafael Pérez-González, 25 Anabelle Manzo-Sandoval, Fernando Díaz-Otero

[12] World Health Organization. Special Programme on AIDS and Expanded Programme on Immunization JointStatement. Consultation on human immunodeficiency virus (HIV) and routine childhood immunization. Wkly Epidemiol Rec. 1987; 40 (2): p. 297-9. Disponible en: http:// apps.who.int/iris/bitstream/handle/10665/226439/WER6240_297-299.PDF?sequence=1.

[13] Haring CM, Traum J, Hayes FM, Henry BS. Vaccination of calves against tuberculosis with Calmette-Guérin culture, BCG. Hilgardia. 1930; 4 (12): p. 307-94. DOI: 10.3733/hilg.v04n12p307.

[14] Wedlock N, Vesosky B, Skinner MA, de Lisle GW, Orme IM, Buddle BM. Vaccination of cattle with Mycobacterium bovis culture filtrate proteins and interleukin-2 for protection against bovine tuberculosis. Infect Immun. 2000; 68 (10): p. 5809-15. DOI: 10.1128/IAI.68.10.5809-5815.2000.

[15] Buddle BM, Pollock JM, Skinner MA, Wedlock DN. Development of vaccines to control bovine tuberculosis in cattle and relationship to vaccine development for other intracellular pathogens. Int J. Parasitol. 2003; 33 (5-6): p. 555-66. DOI: 10.1016/S0020-7519(03)00060-2.

[16] HaslØv K, Andersen A, Nagai S, Gottschau A, Sorensen T, Andersen P. Guinea pig cellular immune responses to proteins secreted by Mycobacterium tuberculosis. Infect Immun. 1995; 63(3): p. 804-10.

[17] Bosio CM, Orme IM. Effective, nonsensitizing vaccination with culture filtrate proteins against virulent Mycobacterium bovis infections in mice. Infect Immun. 1998; 66 (10): p. 5048-51.

[18] HanLew M, Mohd Nor, Norazmi M, Gee Jun Tye. Enhancement of immune response against Mycobacterium tuberculosis HspX antigen by incorporation of combined molecular adjuvant (CASAC). Molecular Immunology. 2020; 117: p. 54-64. DOI: org/10.1016/j.molimm.2019.10.023

[19] Al-Attiyah R, El-Shazly A, Mustafa AS. Comparative analysis of spontaneous and mycobacterial antigen-induced secretion of Th1, Th2 and pro-inflammatory cytokines by peripheral blood mononuclear cells of tuberculosis patients. Scand J Immunol. 2012; 75 (6): p.623-632. DOI: abs/10.1111/j.1365-3083.2012. 02692.x

[20] Norma Oficial Mexicana NOM-031-ZOO-1995. Campaña Nacional Contra la Tuberculosis Bovina (Mycobacterium bovis). Secretaria de Agricultura, Ganadería y Desarrollo Rural (SAGAR). 1995. Disponible en: http://www.dof.gob.mx/nota_detalle. php?codigo $=4874790 \&$ fecha $=08 / 03 / 1996$.

[21] Walravens K, Marché S, Rosseels V, Wellemans V, Boalaert F, Huygen K, Godfroid J. IFN- $\gamma$ diagnostic tests in the context of bovine mycobacterial infections in Belgium. Vet Immunol Immunopathol. 2002; 87 (3-4): p. 401-6. DOI: 10.1016/S0165-2427(02)00092-2. 
Evaluación experimental de vacuna BCG y extracto proteico en bovinos, vía expresión de citocinas

[22] Estrada CC, Díaz OF, Arriaga DC, Villegas SN, Pérez GR, González SD. Concordancia de la PCR y métodos rutinarios para el diagnóstico de tuberculosis bovina. Vet Méx. 2004; 35 (3): p. 225-36.

[23] van Soolingen D, van der Zanden AG, de Haas PE, Noordhoek GT, Kiers A, Foudraine NA, et al. Diagnosis of Mycobacterium microti infections among humans by using novel genetic markers. J Clin Microbiol. 1998; 36 (7): p. 1840-5.

[24] Cousins DV, Wilton SD, Francis BR. Use of DNA amplification for the rapid identification of Mycobacteriumbovis. VetMicrobiol.1991;27(2):p.187-95.DOI:10.1016/0378-1135(91)90010-D.

[25] Covert J, Splitter G. Detection of cytokine transcriptional profiles bovine peripheral blood mononuclear cells and CD4+ lymphocytes by reverse transcriptase polymerase chain reaction. Vet Immunol Immunopathol. 1995; 49 (1-2): p. 39-50. DOI: 10.1016/0165-2427(95)05451-B.

[26] Chomczynski P, Sacchi N. Single-step method of RNA isolation by acid guanidium thiocynate-phenol-cloroform extraction. Anal Biochem. 1987; 162 (1): p. 156-9. DOI: 10.1006/ abio.1987.9999.

[27] Beltan E, Horgen L, Rastogi N. Secretion of citokines by human macrophages upon infection by pathogenic and non-pathogenic mycobacteria. Microb Pathog. 2000; 28 (5): p. 313-18. DOI: 10.1006/mpat.1999.0345.

[28] Thacker TC, Palmer MV, Waters WR. Associations between cytokine gene expression and pathology in Mycobacterium bovis infected cattle. Vet Immunol Immunopathol. 2007; 119 (3-4): p. 204-13. DOI: 10.1016/j.vetimm.2007.05.009.

[29] Domingo M, Vidal E, Marco A. Pathology of bovine tuberculosis. Res Vet Sci. 2014; 97 : Suplement S20-S29. DOI.org/10.1016/j.rvsc.2014.03.017

[30] Roy A, Tomé-Sánchez I, Romero B, Lorente-Leal V, Infantes-Lorenzo JA, Domínguez M, Martín C, Aguilo N., Puentes E, Rodríguez E, de Juan L, Risalde MA, Gortázar C, Domínguez L. Bezos J. Evaluation of the immunogenicity and efficacy of BCG and MTBVAC vaccines using a natural transmission model of tuberculosis. Vet Res 2019; 50: p. 82. DOI: 10.1186/S13567-019-0702-7

[31] Nugent G, Yockney IJ, Cross ML, Buddle BM. Low-dose BCG vaccination protects free-ranging cattle against naturally acquired bovine tuberculosis. Vaccine. 2018; 36 (48): p. 7338-44. DOI: 10.1016/j.vaccine.2018.10.025. 
Maura Cruz-Fierro, Laura Jaramillo-Meza, Clara Inés Espitia-Pinzón, Rafael Pérez-González, 27 Anabelle Manzo-Sandoval, Fernando Díaz-Otero

[32] Covert J, Splitter G. Detection of cytokine transcriptional profiles bovine peripheral blood mononuclear cells and CD4+ lymphocytes by reverse transcriptase polymerase chain reaction.Vet Immunol Immunopathol. 1995;49 (1-2): p. 39-50. DOI: 10.1016/0165-2427(95)05451-B.

[33] Orme IM and Henao-Tamayo MI. Trying to See the Forest through the Trees: Deciphering the Nature of Memory Immunity to Mycobacterium tuberculosis. Front. Immunol. 2018; 9: p. 461. DOI: 10.3389/fimmu.2018.00461

[34] Lyashchenko K, Whelan AO, Greenwald R, Pollock JM, Andersen P, Hewinson RG, et al. Association of tuberculin-boosted antibody responses with pathology and cell-mediated immunity in cattle vaccinated with Mycobacterium bovis BCG and infected with M. bovis. Infect Immun. 2004; 72 (5): p. 2462-7. DOI: 10.1128/IAI.72.5.2462-2467.2004.

[35] Nugent G, Yockney IJ, Cross ML, Buddle BM. Low-dose BCG vaccination protects free-ranging cattle against naturally acquired bovine tuberculosis. Vaccine. 2018; 36 (48): p. 7338-7344. DOI: 10.1016/j.vaccine.2018.10.025

[36] Dockrell HM. Towards new TB vaccines: What are the challenges?, Pathogens and Disease. 2016; 74 (4): p. ftw016. DOI.org/10.1093/femspd/ftw016

[37] Roperto S, Varano M, Russo V, Lucà R, Cagiola M, Gaspari M, Ceccarelli DM, Cuda G, Roperto F. Proteomic analysis of protein purified derivative of Mycobacterium bovis. J Transl Med. 2017; 15: p. 68. DOI:10.1186/s12967-017-1172-1 